\title{
Behavioral Characteristics of the Juvenile Japanese Surf Clam Pseudocardium sachalinensis in response to Sand Erosion and Deposition Associated with Oscillatory Water Flow
}

\author{
Izumi Sakurai* and Masabumi Seto* \\ ${ }^{*}$ Hokkaido Central Fisheries Experimental Station, Yoichi Hokkaido 046-8555, Japan \\ (Received August 25, 1997)
}

\begin{abstract}
This study examined the behavioral characteristics of juvenile Japanese surf clam Pseudocardium sachalinensis in response to sand erosion and deposition under laboratory conditions, then estimated the fluid conditions critical to wash the clams out of the sand. The juveniles started burrowing downward into sand when their burying depth decreased to less than 1.5 times the shell length due to erosion, and moving upward when the depth increased to more than 2.5 times the shell length due to deposition of sand. Burrowing and climbing actions of the juvenile continued until the depth reached 1.7-2.1 times the shell length once again. The burrowing and climbing speeds were about 1.8 times higher than the speed of erosion or deposition of sand. It was concluded that the juveniles would maintain their position actively in order to avoid being washed out or buried too deeply by adapting their behavior to the dynamic conditions of sand movement. The juveniles were washed out of the sand when the erosion speed exceeded $3.5 \mathrm{~mm} / \mathrm{min}$, and such erosion occurred when oscillatory water flow speeds over a sandy bottom with median particle diameter of $0.3 \mathrm{~mm}$ exceeded more than 45 and $55 \mathrm{~cm} / \mathrm{s}$ at periods of $4 \mathrm{~s}$ and $8 \mathrm{~s}$, respectively.
\end{abstract}

Key words: behavior; surf clam; burying depth; bottom disturbance; Pseudocardium sachalinensis; washing out

The Japanese surf clam Pseudocardium sachalinensis, belonging to the family Mactridae, is found on the upper subtidal sandy bottom in northern Japan, Sakhalin, northern Korea and the Maritime Province of Siberia. In Japan, this clam is commercially harvested and annual catches ranged from 6,703 to 8,886 tons during 1986-1995.

The clams breed from spring to early summer along the coast of Hokkaido in northern Japan, ${ }^{1-4)}$ and their planktonic larvae drift under the surface for about 25-30 days. ${ }^{5)}$ Although the larvae settle further offshore than the adult habitat, ${ }^{\text {s) }}$ the juveniles move toward the shore in the early benthic stage and consequently make recruits to the adult population. ${ }^{5,6}$ However, the juvenile density decreases remarkably during this movement, and the mortality at this time is estimated to be over $99 \%{ }^{7,8)}$ The movement is thought to be driven by a bottom disturbance associated with wave action, which washes the juveniles out of the sand and subsequently transports them physically to the shore..$^{5,9,10)}$ In addition, burial too deep in the sand associated with the disturbance has also been suggested as one of the causes of the juveniles' mortality. ${ }^{11)}$

Some experimental studies concerning the movement and burial actions of $P$. sachalinensis have been carried out to prevent the density decrease and to increase clam production. For example, Watanabe ${ }^{12)}$ evaluated water flow speeds at which formalin-fixed juveniles started to roll on the bottom. Kuwahara and Higano ${ }^{13)}$ and Kuwahara et al. ${ }^{14)}$ proposed a mathematical model predicting the physical movement of the juveniles on the bottom, and verified it by hydraulic model tests. Furthermore, the conditions of sand erosion critical to wash out the juveniles from the sand ${ }^{15}$ and then tolerance of the juveniles to burial too deep ${ }^{16)}$ were examined. In contrast, it has been suggested that the juveniles would actively maintain their position in response to sand erosion or deposition, because many infaunal bivalves are able to move up and down in the sand. ${ }^{17-19)}$ However, behavioral responses of the juveniles to such a disturbance have never been clarified.

This study examined the behavioral characteristics of the juvenile $P$. sachalinensis in response to sand erosion and deposition under laboratory conditions, and then estimated the fluid conditions critical to wash the juveniles out of the sand.

\section{Materials and Methods}

\section{Sampling and rearing}

The juvenile clams of $P$. sachalinensis (shell length \pm standard deviation $12.5 \pm 2.4 \mathrm{~mm}$, age $<1$ year) were collected at $7 \mathrm{~m}$ depth along the coast of Tomakomai, Hokkaido ( $\left.42^{\circ} 37^{\prime} \mathrm{N}, 141^{\circ} 36^{\prime} \mathrm{E}\right)$, in March 1995 , and were reared for 5 months in a seawater tank which was kept at a temperature of 8 or $20^{\circ} \mathrm{C}$ to acclimate them to the following experimental conditions. Sand (median particle diameter $=0.3 \mathrm{~mm}$ ) was set on the tank bottom, with a sand depth of about $10 \mathrm{~cm}$, because the burying depth of juvenile $P$. sachalinensis is about twice their shell length. ${ }^{20)}$ The juveniles were fed on the microalga Tetraselmis tetrathele with a concentration of about 10,000 cell $/ \mathrm{ml}$ in the tank. 


\section{Experimental procedure}

The experiments were conducted using a vertical watercirculating tunnel with an observation unit $1.5 \mathrm{~m}$ long, 0.3 $\mathrm{m}$ wide and $0.35 \mathrm{~m}$ in height (Fig. 1). An oscillatory water flow would be generated in the water tunnel by a propeller built in the lower central region of the tunnel and connected with an electric motor. Water flow speed and its period were adjusted by setting the rotary speed and direction of the motor by a computerized control program.

The flowing experiments were carried out. Firstly, the bottom of the observation unit was covered with about 10 $\mathrm{cm}$ depth of sand which was leveled flat, and then the water tunnel was filled with filtered seawater to the depth of $35 \mathrm{~cm}$. Secondly, after measuring the shell length to the nearest $0.1 \mathrm{~mm}$ with a sliding caliper, each juvenile was glued to a plastic rod $40 \mathrm{~mm}$ long and $0.5 \mathrm{~mm}$ in diameter on their right valve (Fig. 2) in order to examine its behavior in the sand. Thirdly, ten juveniles attached to rods for each experiment were placed on the surface of the sandy bottom and left to burrow into the sand. Finally, erosion and deposition of sand were generated by raising the water flow speed over the sandy bottom from 20 up to $55 \mathrm{~cm} / \mathrm{s}$ at $5 \mathrm{~cm} / \mathrm{s}$ steps, each step lasting 60 minutes, and the movements of the rods were recorded using video tape simultaneously with the disturbance of the sandy bottom. The maximum values of the flow speeds were measured in the central point of the observation unit by using an electromagnetic current meter (Kenek Co., Ltd.; VM-201H). The water temperature was maintained at 8 or $20^{\circ} \mathrm{C}$ within the water tunnel, because the burrowing speed and burying depth of $P$. sachalinensis at $5-10^{\circ} \mathrm{C}$ are different from those at $15-25^{\circ} \mathrm{C} .^{20)}$ Periods of 4 or $8 \mathrm{~s}$ of water flow speeds were selected. In addition, the bottom was re-established after every trial in which four cases were tested for each water temperature and period.

The following experiment was carried out in order to examine whether attachment to the rod affected the juveniles' behavior. Firstly, a juvenile with a shell length of $10.5 \mathrm{~mm}$, which had been fixed with $10 \%$ formalin solution, was glued to the rod in the same way as described above, and then buried in the sand at a depth of twice the shell length. Next, the movement of the rod was observed at water flow speeds of $10-80 \mathrm{~cm} / \mathrm{s}$ with periods of 4 and 8 seconds. In addition, we compared the mean burrowing speeds $^{20)}$ of each of ten juveniles with and without a rod in a steady-state condition. As a result, the rod attached to the fixed juvenile did not bend in the flow direction until

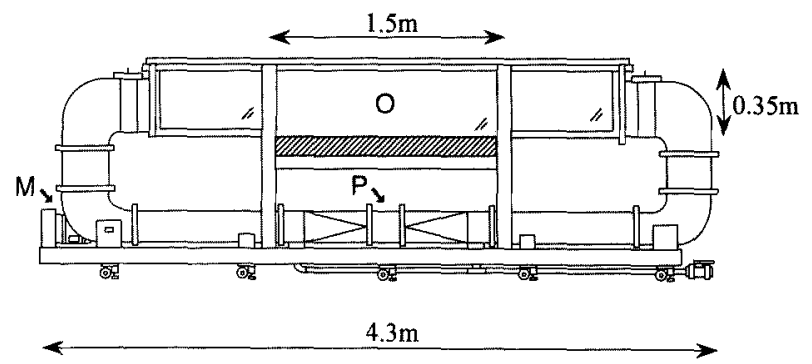

Fig. 1. Schematic diagram of vertical water-circulating tunnel. $M$, variable speed motor; $P$, propeller built-in space; $O$, observation unit wherein shaded portion represents sand. the water flow speed exceeded $60 \mathrm{~cm} / \mathrm{s}$ at both periods, and there was no significant difference between the mean burrowing speeds of ten juveniles with and without rods. Therefore, we concluded that the rod attachment did not influence the juvenile's behavior at water flow speeds of $20-55 \mathrm{~cm} / \mathrm{s}$.

\section{Analysis}

Time series of the position of the juvenile ( $\mathrm{P}: \mathrm{mm})$ relative to the surface (S: $\mathrm{mm}$ ) of the sandy bottom were calculated by measuring the length ( $\mathrm{L}: \mathrm{mm}$ ) of rod protruding from the surface of the sandy bottom, the distances from the floor of the water-tunnel to the surface of the sand (S: $\mathrm{mm}$ ) and to the tip of the rod (B: $\mathrm{mm}$ ). These were measured on the screen of the video recorder to the nearest 1 $\mathrm{mm}$ with a ruler every three minutes (Fig. 2). P was estimated according to the following equation:

$$
\mathrm{P}=\mathrm{S}-(40-\mathrm{L})(\mathrm{B}-\mathrm{S}) / \mathrm{L}
$$

Consecutive changes of $P$ from the $\mathrm{i}$-th to $(\mathrm{i}+\mathrm{n})$-th measurement were regarded as a series of voluntary movements of the juvenile, so burrowing and climbing actions of the juvenile were defined as the fall and rise of $P$, respectively.

Next, the burying depths at the time that the juvenile started (Ds) and ended (De) burrowing or climbing action were estimated from the following equation in each time series change:

$$
\text { Ds or } \mathrm{De}=(\mathrm{S}-\mathrm{P}+\lambda) / \lambda
$$

where Ds and De were standardized in relation to the shell length $(\lambda: \mathrm{mm})$, because the burying depth of $P$. sachalinensis increases in proportion to the shell length. ${ }^{21)}$

The burrowing and climbing speeds of the juveniles $(\mathrm{Vb}$ and $\mathrm{Vc}: \mathrm{mm} / \mathrm{min}$, respectively) were estimated according to the following equations:

$$
\begin{aligned}
& V b=\left(P_{i}-P_{i+n}\right) / 3 n \\
& V c=\left(P_{j+n}-P_{i}\right) / 3 n
\end{aligned}
$$

where $P_{i}$ and $P_{i+n}$ are the $i-t h$ and $(i+n)$-th measurements of $P$, respectively.

Erosion and deposition speeds of the sand (Ue and Ud: $\mathrm{mm} / \mathrm{min}$, respectively) were estimated from the equations:

$$
\begin{aligned}
& U e=\left(S_{i}-S_{i+n}\right) / 3 n \\
& U d=\left(S_{i+n}-S_{i}\right) / 3 n
\end{aligned}
$$

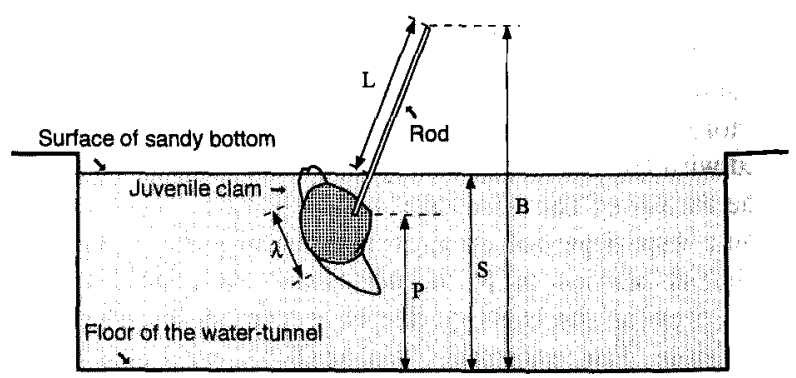

Fig. 2. Schematic diagram showing parameters for estimating burying depths of the juvenile surf clam's position. $P$, position of the juvenile; $S$, distance from floor of the water-tunnel to surface of sandy bottom; $L$, length of rod protruding from the surface of sandy bottom; $B$, distance from the floor to the tip of rod; $\lambda$, shell length of the juvenile. 
where $S_{i}$ and $S_{i+n}$ are the $i$-th and $(i+n)$-th measurements of $S$, respectively.

\section{Results}

The sand surface in which the juveniles buried themselves fluctuated with the formation and movement of sand ripples due to the oscillatory water flow. An example of the time series of $\mathbf{P}$ and $\mathbf{S}$ at different experimental conditions is shown in Fig. 3. The juveniles mostly burrowed and moved upward in the sand when sand erosion and deposition occurred, respectively.

Ds and De were subsequently averaged for each specimen, action and experimental condition, and the effects of water temperature and periods on the burying depths were analyzed by using a 2-factor ANOVA. The results are shown in Tables 1 and 2. There was no significant difference due to water temperature or period $(P>0.05)$. Ds and

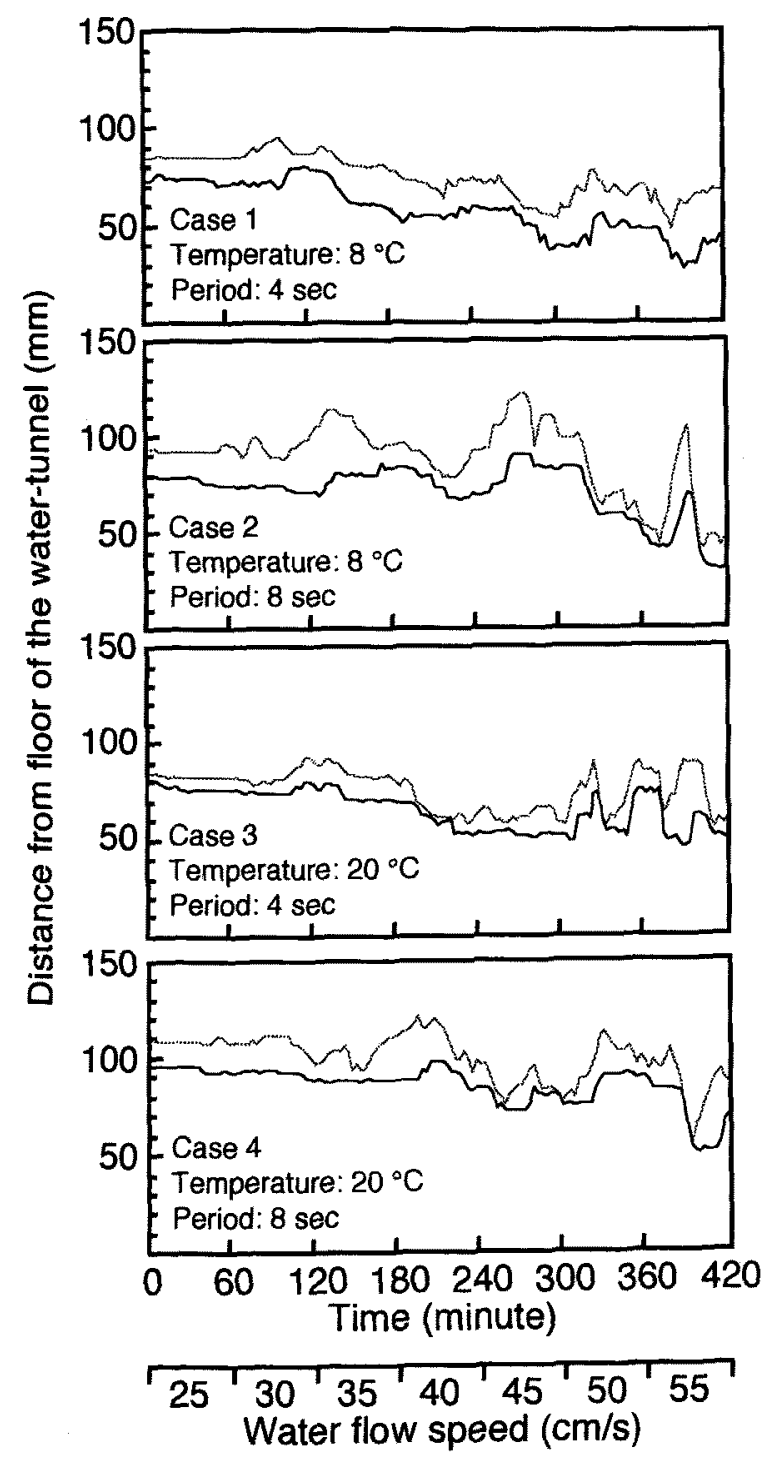

Fig. 3. Example of time series of the juvenile surf clam's position (solid lines) relative to surface of sandy bottom (dotted lines) at different experimental conditions.
De were therefore averaged for each action regardless of water temperature and period (Fig. 4). The mean values of Ds and De were 1.51 and 1.74 for burrowing, and 2.54 and 2.10 for climbing, respectively. The differences between Ds and De were highly significant in both actions (t-test, $\mathrm{P}<0.01$ )

Table 1. Summary of ANOVA examining the effects of water temperature and period on burying depth (Ds) of the juvenile at the time that the movement started

\begin{tabular}{lrrrr}
\hline \multicolumn{1}{c}{ Source } & d.f. & MS & F & P \\
\hline Burrowing & & & & \\
$\quad$ Temperature & 1 & 0.013 & 1.772 & 0.192 \\
$\quad$ Period & 1 & 0.003 & 0.384 & 0.539 \\
Temperature $\times$ Period & 1 & 0.003 & 0.340 & 0.564 \\
$\quad$ Error & 36 & 0.007 & & \\
Climbing & & & & \\
$\quad$ Temperature & 1 & 0.016 & 0.230 & 0.635 \\
$\quad$ Period & 1 & 0.026 & 0.374 & 0.545 \\
$\quad$ Temperature $\times$ Period & 1 & 0.173 & 2.505 & 0.122 \\
$\quad$ Error & 36 & 0.690 & & \\
\hline
\end{tabular}

d.f.: degree of freedom, MS: mean square, $F$ : variance ratio, $P$ : level of significance.

Table 2. Summary of ANOVA examining the effects of water temperature and period on burying depth (De) of the juvenile at the time that the movement ended

\begin{tabular}{lrrrr}
\hline \multicolumn{1}{c}{ Source } & d.f. & MS & F & P \\
\hline Burrowing & & & & \\
$\quad$ Temperature & 1 & 0.021 & 2.096 & 0.156 \\
$\quad$ Period & 1 & 0.015 & 1.514 & 0.227 \\
$\quad$ Temperature $\times$ Period & 1 & 0.002 & 0.155 & 0.696 \\
$\quad$ Error & 36 & 0.010 & & \\
Climbing & & & & \\
$\quad$ Temperature & 1 & 0.002 & 0.077 & 0.784 \\
$\quad$ Period & 1 & 0.007 & 0.310 & 0.581 \\
$\quad$ Temperature $\times$ Period & 1 & 0.018 & 0.812 & 0.374 \\
Error & 36 & 0.022 & & \\
\hline
\end{tabular}

d.f.: degree of freedom, MS: mean square, F: variance ratio, P: level of significance.

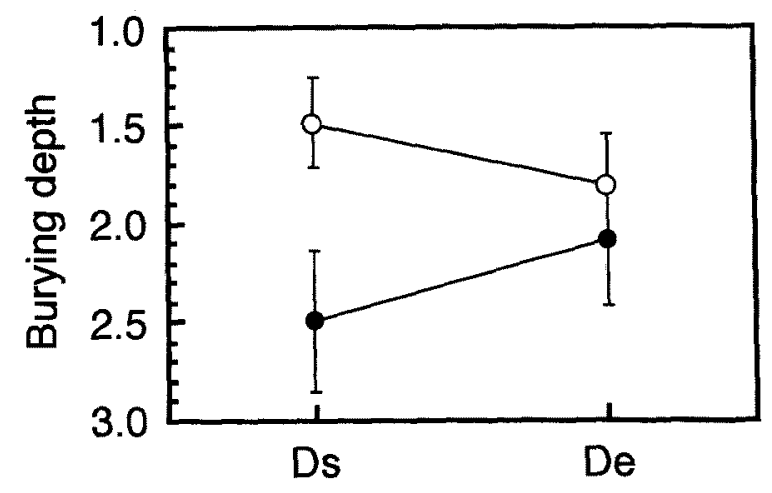

Fig. 4. Mean burying depth of the juvenile surf clam at the time that movement of the juvenile started (Ds) and ended (De). Burying depth is given by $(S-P+\lambda) / \lambda$, where $S, P$ and $\lambda$ are the same as in Fig. 2. Open and solid circles represent the depth at the time that the juveniles burrowed and climbed up in the sand, respectively. Each value denotes the mean with standard deviation indicated by a vertical bar. 
Table 3. Summary of ANOVA examining the effects of water temperature and period on $\mathrm{Vb} / \mathrm{Ue}$ and $\mathrm{Vc} / \mathrm{Ud}$ at which the juvenile surf clam buried themselves in the sand

\begin{tabular}{lrrrc}
\hline \multicolumn{1}{c}{ Source } & d.f. & MS & F & P \\
\hline$V b /$ Ue & & & & \\
Temperature & 1 & 0.009 & 0.024 & 0.877 \\
Period & 1 & 0.250 & 0.648 & 0.426 \\
Temperature $\times$ Period & 1 & 0.360 & 0.934 & 0.340 \\
$\quad$ Error & 36 & 0.385 & & \\
$V c /$ Ud & & & & \\
Temperature & 1 & 0.108 & 0.132 & 0.719 \\
Period & 1 & 1.405 & 1.716 & 0.199 \\
Temperature $\times$ Period & 1 & 2.338 & 2.855 & 0.100 \\
Error & 36 & 0.819 & & \\
\end{tabular}

d.f.: degree of freedom, MS: mean square, F: variance ratio, P: level of sig nificance.

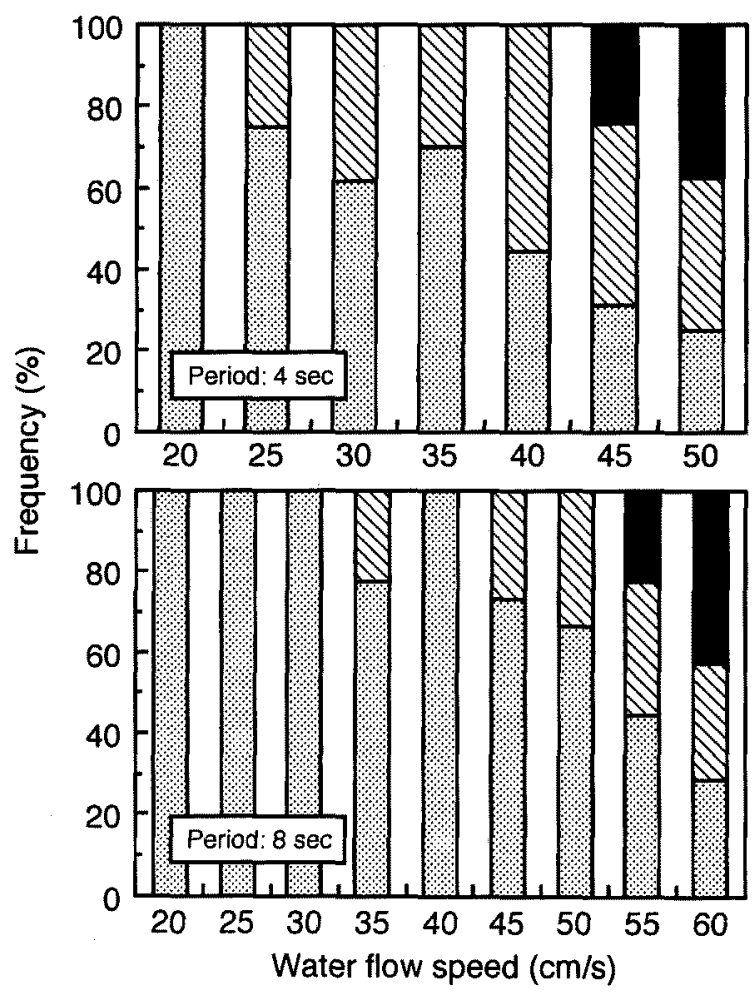

Fig. 5. Relationship between water flow and erosion speed at the experiment. Dotted, shaded and solid bars represent the erosion speeds of $0-1.5,1.5-3.5$ and $>3.5 \mathrm{~mm} / \mathrm{min}$, respectively.

Regression lines between $\mathrm{Ue}$ and $\mathrm{Vb}$, or $\mathrm{Ud}$ and $\mathrm{Vc}$ which passed through the origin were calculated for each specimen and experimental condition. As a result, all slopes (i.e, $\mathrm{Vb} / \mathrm{Ue}$ and $\mathrm{Vc} / \mathrm{Ud}$ ) were significantly different from zero $(P<0.05)$, so the effects of water temperature and period on $\mathrm{Vb} / \mathrm{Ue}$ and $\mathrm{Vc} / \mathrm{Ud}$ were analyzed using a 2factor ANOVA (Table 3). There was no significant difference due to water temperature or period $(P>0.05)$. Consequently, each slope was averaged regardless of water temperature and period. The mean values of $\mathrm{Vb} / \mathrm{Ue}$ and $\mathrm{Vc} / \mathrm{Ud}$ were 1.82 and 1.79 , respectively.

The juveniles were unable to maintain their position and were washed out of the sand when Ue exceed 3.5 $\mathrm{mm} / \mathrm{min}$. When washing out, $\mathrm{Vb} / \mathrm{Ue}$ ranged from 0.3 to 0.8 . In addition, values of Ue $>3.5 \mathrm{~mm} / \mathrm{min}$ were observed when water flow speed exceeded 45 and $55 \mathrm{~cm} / \mathrm{s}$ at periods of 4 and $8 \mathrm{~s}$, respectively (Fig. 5). However, values of Ud which were high enough to bury the rod attached to each juvenile completely in the sand were not observed.

\section{Discussion}

\section{Behavior in response to bottom disturbance}

In general, exposed sandy beaches are subjected to severe disturbances on the bottom surface by wave action, and this greatly limits the benthic fauna compared with that of more sheltered beaches. Infaunal bivalves inhabiting such an environment avoid being uncovered by burying themselves deeper, and in other cases maintain their position actively by burying themselves shallower. ${ }^{19}$ In addition, a forced compromise of both characteristics has been reported. ${ }^{22)}$ In the present study, the juveniles of $P$. sachalinensis burrowed deeper when the burying depth decreased below 1.5 times their shell length due to sand erosion, and moved upward when the depth increased to more than 2.5 times the shell length due to deposition of sand. Furthermore, these actions were continued until the juveniles returned to the depth between 1.7 and 2.1 times the length. Therefore, it is suggested that the juveniles actively maintained their position at depths of 1.5-2.5 times the shell length to avoid being either washed out or buried too deeply.

Although the burying depth at $P$. sachalinensis in $5-10^{\circ} \mathrm{C}$ was deeper than that at $15-25^{\circ} \mathrm{C}$ in static flow conditions, ${ }^{20)}$ an effect of water temperature on the depth was not detected in the present study. Differences in the burying depth between static and oscillatory flow conditions could be derived from the fact that bottom disturbance had a stronger influence on the burying depth than water temperature did, because the position-maintaining movements of the juveniles in the disturbed condition would be more frequent than in the stable condition. Furthermore, an effect of period on depth was also not detected. Because the period of water flow influences only the wavelength and amplitude of the sand ripples formed on the bottom surface, ${ }^{23)}$ the period of flow would not affect the actions of juveniles buried in the sand.

In the present study, burrowing and climbing speeds of the juveniles tended to rise with the speed of erosion and deposition, respectively. This suggests that the juveniles adjust the speed of their action to the erosion and deposition speeds. Ansell and Trevallion ${ }^{19)}$ described the vertical motion of infaunal bivalves as follows. The burrowing process is caused by contractions of the retractor muscles with the pedal anchored in the sand and is facilitated by a rocking motion produced by the consecutive action of the retractor muscles, as well as by expulsion of water from the mantle cavity into the sand by adduction of the shell valves immediately before pedal retraction. In contrast, the climbing process involves forcible protraction of the pedal, which is extended, and at the same time straightened from a curved position to lever the shell upwards through the sand; the pedal is then withdrawn into the shell and re-positioned before repetition of the process. 
Thus, the burrowing and climbing actions are caused by successive movements of the pedal and the muscle in unison. We consider that the juveniles of $P$. sachalinensis adjust the speed of their actions in the sand by changing the muscle motion or the repetitive interval of the above processes.

It is also suggested that the juveniles of $P$. sachalinensis maintain their position by moving upward and downward in the sand with the speed of about 1.8 times greater than that of deposition and erosion of sand. This characteristic would involve the risk of energy-loss due to excessive motion, but would have the advantage of preventing washing out or excessively deep burial in the sand. In addition, $P$. sachalinensis generally inhabits exposed sandy beaches which are subjected to wave action. ${ }^{10}$ ) Therefore, it is concluded that the above behavior of the juveniles is well adapted to the dynamic water flow conditions.

\section{Washing out and excessive burial}

In the present study, the juveniles of $P$. sachalinensis were washed out of the sand when erosion speed rose above $3.5 \mathrm{~mm} / \mathrm{min}$. In addition, $\mathrm{Vb} / \mathrm{Ue}$ at the time of washing out ranged from 0.3 to 0.8 . This result agrees with that of Yamashita et al., ${ }^{15)}$ who measured this ratio at fluid conditions with periods of 3.0-3.5 s.

In general, sand transport progresses with increasing flow speeds at the bottom as follows: bedload transport, suspended load transport, formation and removal of sand ripples, and sheet flow, and this series of sand transport modes causes erosion and deposition. ${ }^{23)}$ Sand transport models are defined theoretically by the specific gravity and particle diameter of the sand, the height and period of the waves, and the depth. ${ }^{24-26)}$ However, it is difficult to standardize erosion and deposition speeds by using the models, because the speeds differ according to the location of the ripple (e.g., crest or trough). Therefore, we tried to estimate experimentally water flow speeds under which the juveniles of $P$. sachalinensis would be washed out of the sand, taking the relationship between erosion speed and oscillatory water flow speed into consideration. The estimated water flow speed for washing out on the sandy bottom with a median particle diameter of $0.3 \mathrm{~mm}$ was $>45$ and $>55 \mathrm{~cm} / \mathrm{s}$ at periods of 4 and $8 \mathrm{~s}$, respectively.

Yamashita et $a l .^{15}$ ) reported that juveniles of $P$. sachalinensis which had been washed out could not reburrow into the sand at a flow speed of $45 \mathrm{~cm} / \mathrm{s}$ and a period of $3 \mathrm{~s}$. In the present study, such reburrowing of the juveniles was also not observed at flow speed $>45 \mathrm{~cm} / \mathrm{s}$ and a period of $4 \mathrm{~s}$. On the other hand, Watanabe ${ }^{\mathrm{i2})}$ showed that $P$. sachalinensis with a shell length of $10 \mathrm{~mm}$, which had been fixed by formalin, rolled downstream on the sand when flow speed rose above $17 \mathrm{~mm} / \mathrm{s}$ on a flat bottom. In contrast, $P$. sachalinensis with a shell length of 4$10 \mathrm{~mm}$ could burrow into the sand when flow speed fell below 15 and $20 \mathrm{~cm} / \mathrm{s}$ at periods of 4 and $8 \mathrm{~s}$, respectively. ${ }^{27)}$ Therefore, it is considered that juveniles washed out of the sand would be transported physically without reburrowing until the flow speed fell below $15-20 \mathrm{~cm} / \mathrm{s}$.

Table 4 shows the relationship between bottom depth and wave height with flow speeds at which the juvenile will be washed out and be able to reburrow into the sand, which were calculated by using small amplitude wave theo-
Table 4. Estimated wave height with flow speeds at which the juvenile surf clams inhabited at the depth of 6-9 $\mathrm{m}$ were washed out and were able to reburrow into the sand

\begin{tabular}{cccccc}
\hline Depth & \multicolumn{2}{c}{$4 \mathrm{sec}$} & & \multicolumn{2}{c}{$8 \mathrm{sec}$} \\
\cline { 5 - 6 } \cline { 5 - 6 } & $\begin{array}{c}\text { washing out } \\
(45 \mathrm{~cm} / \mathrm{s})\end{array}$ & $\begin{array}{c}\text { Reburrowing } \\
(15 \mathrm{~cm} / \mathrm{s})\end{array}$ & $\begin{array}{c}\text { Washing out } \\
(55 \mathrm{~cm} / \mathrm{s})\end{array}$ & $\begin{array}{c}\text { Reburrowing } \\
(20 \mathrm{~cm} / \mathrm{s})\end{array}$ \\
\hline $6 \mathrm{~m}$ & $2.5 \mathrm{~m}$ & $0.5 \mathrm{~m}$ & & $1.1 \mathrm{~m}$ & $0.4 \mathrm{~m}$ \\
$7 \mathrm{~m}$ & $2.1 \mathrm{~m}$ & $0.9 \mathrm{~m}$ & & $1.2 \mathrm{~m}$ & $0.4 \mathrm{~m}$ \\
$8 \mathrm{~m}$ & $1.7 \mathrm{~m}$ & $1.4 \mathrm{~m}$ & & $1.3 \mathrm{~m}$ & $0.4 \mathrm{~m}$ \\
$9 \mathrm{~m}$ & $1.5 \mathrm{~m}$ & $1.1 \mathrm{~m}$ & $1.4 \mathrm{~m}$ & $0.5 \mathrm{~m}$ \\
\hline
\end{tabular}

Each value were calculated by using small amplitude wave theory. ${ }^{23}$ )

ry. ${ }^{23)}$ At depths of 6-9 $\mathrm{m}$ under the sea surface where the juveniles live, ${ }^{5}$ it is estimated that they would be washed out of the sand when the wave height rose above 1.5-2.5 and 1.1-1.4 $\mathrm{m}$, and would be able to reburrow into the sand when the height fell below $0.5-1.1$ and $0.4-0.5 \mathrm{~m}$, at periods of 4 and $8 \mathrm{~s}$, respectively. Such fluctuation of wave height could often be observed within one day on exposed sandy beaches where the surf clams live. ${ }^{28)}$ Consequently, it is suggested that the juveniles would frequently and repeatedly be washed out of the sand and would then roll onto or reburrow into the sand under the sea. On the other hand, it is known that the juvenile habitat of $P$. sachalinensis gradually moves toward the shore in the early benthic stage. ${ }^{5,6,9,10)}$ In addition, the burial depth of $P$. sachalinensis increases with the growth. ${ }^{21)}$ Therefore, we conclude as follows: the movement of the juvenile habitat would be caused physically by the repetition of being washed out, rolling, and reburrowing as a result of wave action, and the habitat would become stable finally as the juveniles grow to a size at which the frequency of being washed out falls.

In the present study, we could not examine the effect of excessively deep burial on mortality of the juveniles, because speeds of sand deposition at which the juveniles were unable to climb up were not observed. However, Watanabe ${ }^{16)}$ reported that $P$. sachalinensis with a shell length of 5.0-9.5 mm could move up through the sand to just below the bottom surface when $45 \mathrm{~cm}$ thickness of sand was deposited on their habitat in a day. Therefore, it is suggested that mortality of the juveniles due to deep burial would not occur under the wave condition in which deposition alternates with erosion.

Acknowledgments This work was funded by the Hokkaido Developmental Agency. We wish to express our appreciation to Dr. $T$. Yamashita, Faculty of Engineering, Hokkaido University, for his helpful advice.

\section{References}

1) N. Takahashi and K. Takano: Histological studies on the reproductive cycle of the surf clam, Spisula sachalinensis-1. Seasonal changes in the testis. Nippon Suisan Gakkaishi, 36, 337-344 (1970).

2) N. Takahashi and K. Yamamoto: Histological studies on the reproductive cycle of the surf clam, Spisula sachalinensis-II. Seasonal changes in the ovary. Nippon Suisan Gakkaishi, 36, 345$352(1970)$.

3) N. Takamaru: On the breeding season of the surf clam, Spisula sachalinensis (Schrenk) in Tokachi. J. Hokkaido Fish. Exp. Stn., 33, 1-8 (1976) (in Japanese). 
4) I. Sakurai, T. Miyamoto, and M. Kurata: Breeding season of the Japanese surf clam Pseudocardium sybillae in Tomakomai and Shizunai, southwest Hokkaido. Sci. Rep. Hokkaido Fish. Exp. Sin., 39, 45-52 (1992).

5) T. Hayashi, K. Terai, and K. Arima: Studies on the planktonic larvae and young shells of Japanese surf clam, Spisula sachalinensis Schrenck, on the coast of Yakumo, Oshima Prov., Hokkaido. Sci. Rep. Hokkaido Fish. Exp. Stn., 7, 8-71 (1967).

6) N. Takamaru: On the migration of the Japanese surf clam, Pseudocardium sybillae (Valenciennes). J. Hokkaido Fish. Exp. Stn., 38, 222-233 (1981) (in Japanese).

7) K. Arima and T. Hayashi: Studies on the young shells of Japanese surf clam, Spisula sachalinensis (Schrenck), on the coast of Yakumo, Oshima Prov., Hokkaido. Sci. Rep. Hokkaido Fish. Exp. Stn., 10, 51-68 (1969).

8) N. Takamaru: The growth and mortality of the young Japanese surf clam, Pseudocardium sybillae (Valenciennes). J. Hokkaido Fish. Exp. Stn., 38, 296-305 (1981) (in Japanese).

9) N. Takamaru: On the aquaculture studies of the Japanese surf clam, Pseudocardium sybillae in Hokkaido. Fish. Eng., 21, 43-47 (1984) (in Japanese).

10) T. Hayashi: Occurrence, distribution and mortality of juvenile surf clam, Pseudocardium sybillae (Valenciennes), in natural beds. Fish. Eng., 24, 45-52 (1988) (in Japanese).

11) S. Choe: Migration of the Japanese little necked clam, Ruditapes philippinarum. Suisanzoshoku, 11, 13-24 (1963) (in Japanese).

12) E. Watanabe: Experimental study on the decrease of surf clam under wave action. Monthly Rep. Civil Eng. Res. Inst., 351, 3-15 (1982) (in Japanese).

13) H. Kuwahara and J. Higano: Numerical method for estimating onoffshore movement of the bivalves by waves. Proc. of Coastal Eng. JSCE, 40, 311-315 (1993).

14) H. Kuwahara, J. Higano, Y. Nakamura, and N. Mimura: Validity of on-offshore movement model of bivalves due to wave and the movement mechanism. Proc. of Coastal Eng. JSCE, 41, 376-380 (1994).

15) T. Yamashita, A. Wada, G. Matsuoka, K. Yano, and S. Akeda: Experimental study on behavior of bivalves under oscillatory flow. Proc. of Coastal Eng. JSCE, 42, 506-510 (1995).

16) E. Watanabe: Experimental study on the decrease of surf clam ba- bies under wave action and burying condition in the sand. Monthly Rep. Civil Eng. Res. Inst., 359, 24-41 (1983) (in Japanese).

17) E. R. Trueman, A. R. Brand, and P. Davis: The dynamics of burrowing of some common littoral bivalvia. J. Exp. Biol., 44, 469. 492 (1966)

18) E. R. Trueman: The burrowing activities of bivalves. Synp. zool. soc. Lond., 22, 167-186 (1968).

19) A. D. Ansell and A. Trevallion: Behavioral adaptations of intertidal molluscs from a tropical sandy beach. J. Exp. Mar. Biol. Ecol., 4, 9-35 (1969).

20) I. Sakurai, M. Seto, and S. Nakao: Effects of water temperature, salinity and substrata on burrowing behaviors of the three bivalves, Pseudocardium sachalinensis, Mactra chinensis, and Ruditapes philippinarum. Nippon Suisan Gakkaishi, 62, 878-885 (1996).

21) K. Nashimoto, T. Kojima, and O. Sato: Burrowing behavior of Japanese surf clams. Bull. Fac. Fish. Hokkaido Univ., 37, 171-180 (1986).

22) Y. Kondo and G. Stace: Burrowing ability and life position of toheroa (Paphies ventricosa: Mesodesmetidae), an unusually large, deep-burrowing ocean beach bivalve endemic to New Zealand. Venus, 54, 67-76 (1995).

23) S. Horikawa: Coastal engineering. Tokyo University Press, Tokyo, 1991, pp. 245-281 (in Japanese).

24) T. Ishihara and T. Sawaragi: On the critical velocity and critical water depth of sand movement, and the rate of sediment transport under wave action. Proc. 7th Japanese conf. on Coastal Eng., 4-58 (1960).

25) S. Sato and N. Tanaka: Sand movement on horizontal bed due to wave action. Proc. 9th Japanese Conf. on Coastal Eng., 95-100 (1962).

26) S. Horikawa and A. Watanabe: Studies on sand movement by wave action. Proc. 13th Japanese Conf. on Coastal Eng., 126-134 (1966)

27) I. Sakurai, K. Nakajima, and T. Yamashita: Effect of oscillatory water flow on burrowing behaviors of the Japanese surt clam Pseudocardium sachalineusis, Nippon Suisan Gakkaishi, 64, 406-411 (1998).

28) I. Sakurai, K. Kurata, and E. Abe: Age structure and mortality of the sunray surf clam Mactra chinensis off Tomakomai, southwest Hokkaido. Fisheries Sci., 62, 168-172 (1996). 